\title{
Using Plastic Bags in Roadways
}

\author{
Gabriela Kuran, Catarina Figueiredo Mendes, and Gautham Das
}

\begin{abstract}
Mass production of plastics began just six decades ago and has rapidly accelerated, creating 8.3 billion metric tons of waste, which exists mostly as disposable products that end up as trash. Incorporating plastic waste in the design of roads can be one alternative for preventing further pollution and minimizing existing plastic waste. The purpose of this research is to characterize the potential risks associated with the implementation of plastic to asphalt. Samples included the following Low-Density Polyethylene (LDPE) plastic bags, and plastic pellets. These samples were tested for the concentration of Lead ( $\mathrm{Pb}$ ), Cadmium (Cd), and Chromium (Cr). All samples were digested and analyzed using: Inductively Coupled Plasma-Atomic Emission Spectroscopy (ICP-AES) testing, Atomic Absorption Spectrometer (AA) testing, X-Ray Fluorescence Spectrometer (XRF) testing, and the Fourier Transform Infrared Spectrophotometer (FTIR). XRF results indicated that black plastic bags had $0.132 \%$ of $\mathrm{Cr}$ and white plastic bags had $0.01 \%$ of $\mathrm{Cr}$. All the other metals in consideration were non-detect or in the parts per trillion range. The extraction results using the ICP-AES indicated $\mathrm{Pb}$ concentrations of $12 \mathrm{mg} / \mathrm{kg}$ which does not exceed the USEPA permissible standards. Additional testing for Manganese (Mn), Nickel (Ni), and Antimony (Sb) will be conducted in upcoming procedures.
\end{abstract}

Index Terms-Heavy metals in plastic, LDPE, plastics, sustainability.

\section{INTRODUCTION}

Plastics are defined as polymeric compounds with a high molecular mass and are classified by the chemical structure of a polymer's backbone and side chains. Some advantages of plastics are that they have high thermal and electrical insulation properties while remaining low-cost, lightweight, strong, and durable corrosion-resistant materials [1]. Typically, light weight plastics are simple polymers consisting of random-length (but generally very long) chains made up of two-carbon units, as shown in Fig. 1.

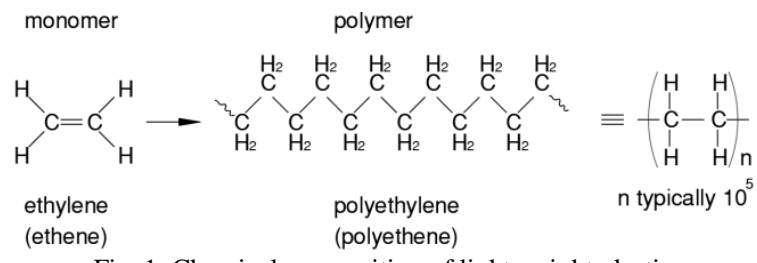

Fig. 1. Chemical composition of light weight plastic.

From 1950 until about 2012, plastics have seen a growth in production of about 8.7 percent per year, increasing from 1.7 million tons to the nearly 300 million tons present today [2]. Among the various areas of industry that demand plasticsincluding transportation, construction, health care, food

Manuscript received May 9th, 2019; revised June 4, 2019.

The authors are with Wentworth Institute of Technology, City of Boston, Massachusetts, United States (e-mail: gabby3k7@gmail.com, fmendescatarina@gmail.com). products, telecommunications, and consumer goods- the packaging industry is responsible for the majority of plastic demand, representing 42 percent of the demand in the United States and 40 percent in Europe [3].

From the large volume of plastics being consumed, a large quantity of end-of-life plastics are disposed of to landfills [4]. However, the disposal of plastic products in landfills has become a concern due to the continuous decrease of available space in landfills as well as the potential for plastic leaching when plastic material is deposited in an unlined landfill [5]. During the manufacturing process of plastic bags and packaging, different types of polymers are often used. These include heavy metals and additives [6]. In addition, the compounds within plastic break down very slowly due to their high molecular mass and the formation of polymers, resulting in a very slow decomposition [7], [8]. Once in landfills, these additives can potentially leach into the environment throughout their life-cycle when exposed to light, heat, or other stimulants [9], consequently representing a threat to the health of the population and environment.

The urgent need to reduce plastic presence in the environment has resulted in some countries, such as the Netherlands and India, to incorporate plastic into their roadways as a substitute of bitumen. Both plastic and bitumen- which is the major component of asphalt- originate from petroleum. Thus incorporating plastic in asphalt would serve as a possible alternative to recycling plastic. However, most countries are hesitant to incorporate plastic products into roadways as they believe that plastic breaks down into microplastics, which have the ability to adsorb various other contaminants [10].

The construction of roads required large amounts of various materials. Therefore, incorporating even small quantities of reclaimed material into the design of roadways could lead to the repurpose of significant quantities of polyethylene waste [11]. The incorporation of plastics into the design of roads has been proven by studies to add several advantageous qualities to asphalt. Some of these include increased strength, improved binding, and better surface conditions for a prolonged period of exposure to varying climate conditions, thus making tar roads suitable even during heavy traffic [12]. Thus, this alternative can prove to be an easy method to achieve sustainability within infrastructure.

Among the various types of plastic, this research primarily focuses on the recycling of Low-Density Polyethylene (LDPE) such as Plastic Bags (PB) and Plastic Pellets (PP). Due to demand within the retail industry and among consumers themselves, PBs have gained increasing popularity [13], [14]. Annually, about 500 billion to one trillion PBs are consumed worldwide; i.e., 1.4-2.7 billion per day, the equivalent of roughly one million bags used per minute [15]. In a study produced by Redford in "Sources of 
plastic pellets in the aquatic environment," plastic pellets are described as "ovoid, cylindrical or spherical pieces of polymer, between 2 and $5 \mathrm{~mm}$ in diameter and it is in this form that raw plastics are transported to plastic processing facilities prior to forming or molding into consumer items", [16]. According to data obtained from the shorelines, from the open ocean and from debris ingested by seabirds, there is an indication that the quantities of PP are increasing in the environment ( $10 \%$ by weight of strandline material) [17].

It is critical, however, to understand the potential of leaching of LDPE when incorporated with bitumen, as the recent increase in use of recycled plastic materials has been associated with the increase of human exposure to heavy metals [18]. As previously discussed, heavy metals are commonly used in plastic production and to recycle plastic materials. High levels of heavy metals were detected in some $\mathrm{PE}$ rubbish as well as in grocery bags, where $\mathrm{Cr}$ and $\mathrm{Pb}$ were found to exceed standards in the trash bags. Different metals were found to be within permissible standards. Moreover, no similarity was found between PBs of different colors and polymer types in the case of metal contents [19].

In this study, $\mathrm{Cd}, \mathrm{Cr}, \mathrm{Ni}, \mathrm{Pb}, \mathrm{Mn}$ and $\mathrm{Sb}$ were quantified in LDPE PB and PP, using inductively coupled plasma-atomic emission spectrometry (ICP-AES), Atomic Absorption Spectrometer (AA), X-Ray Fluorescence Spectrometer (XRF), and the Fourier Transform Infrared Spectrophotometer (FTIR). All have the potential to cause serious health effects with prolonged exposure and/or ingestion and all are considered carcinogens by the Agency for Toxic Substances and Disease Registry [20].

According to the Environmental Protection Agency (EPA), serious health effects have been associated with each of these contaminants studied throughout this research. Exposure and/or ingestion to $\mathrm{Cd}$ can cause pulmonary irritation and kidney disease. Exposure to $\mathrm{Cr}$ can lead to lung cancer, bronchitis, pneumonia, and other respiratory effects. Lead poisoning can cause severe headaches, abdominal pain and various complications in the nervous system. Prolonged exposure or ingestion of $\mathrm{Sb}$ can lead to serious health problems such as lung disease, heart problems, severe vomiting, stomach ulcers and diarrhea [21]. Exposure to $\mathrm{Ni}$ can cause skin problems and increased risk of lung and nasal cancers. The health effects of Mn in humans include lethargy, increased muscle tonus, tremor, and mental disturbances.

To act as stabilizers and pigments, heavy metals are added to PBs. These metal contents may vary region to region [22], [23]. When these PBs are disposed of in dumpsites, there is a potential for the spreading of toxic metals. These toxic metals will then result in contamination of nearby soil, plants, and water bodies [24]. As mentioned, heavy metals used as additives may be enfolded in PBs, meaning that they are not chemically bound within the polymer matrix. Once these metals are leached out, they spread into the surrounding environment. In the long-term, the environment will be exhausted by such contamination in addition to the growing human demand for food and drinking water [25]-[27].

The objective of this research is to evaluate the quantity of contaminants present in LDPE plastic bags and plastic pellets. To evaluate the presence of contaminants in plastic, several laboratory procedures such as an acid digestion, an extraction and XRF testing were conducted. Upon completion of this research, it is hypothesized that plastic products can be used as an alternative to bitumen in asphalt.

\section{METHODS}

Reams of plastic bags in multiple colors were either collected or purchased from grocery stores in Boston, Massachusetts. These samples were chosen based upon the frequent accessibility and use of plastic bags among typical American consumers. Plastic bag colors were chosen based on popularity and include: black, brown, and white. Plastic pellets were generously donated by New York-based company Domino Plastics Company and are free of dyes. All aforementioned plastics are of the low-density polyethylene variety.

For the purposes of consistency, the plastic bags were hand-cut with clean scissors into $1 \mathrm{~cm}$-wide strips with varying lengths averaging about $30 \mathrm{~cm}$. There was no necessary preparation for the plastic pellets for any of the testing. Table I summarizes the materials tested in this research.

\begin{tabular}{|c|c|c|c|}
\hline Polymer Class & Color & Use & Sample ID \\
\hline \multirow{6}{*}{$\begin{array}{c}\text { Low Density } \\
\text { Polyethylene } \\
\text { (LDPE) }\end{array}$} & Black & Grocery Bag & 1-Bl \\
\hline & Brown & Grocery Bag & $1-\mathrm{Br}$ \\
\hline & White & Grocery Bag & $1-W$ \\
\hline & Black & Trash Bag & 2-Bl \\
\hline & White & Trash Bag & $2-W$ \\
\hline & Transparent & Pellet & $3-T$ \\
\hline \multicolumn{4}{|c|}{$\begin{array}{l}1=\text { Grocery } \mathrm{Bag}, 2=\text { Trash Bag, } 3=\text { Pellet } \\
\mathrm{Bl}=\text { Black, } \mathrm{Br}=\text { Brown, } \mathrm{W}=\text { White }, \mathrm{T}=\text { Transparent }\end{array}$} \\
\hline
\end{tabular}

\section{A. Acid Digestion}

The acid digestion procedure for this research was done in accordance to EPA 3051 and 200.2. The plastic bags (1-B1, $1-\mathrm{Br}, 1-\mathrm{W})$ were initially sorted based on color and type of use. The plastic bags were cut to $1-\mathrm{cm}$ wide and $30-\mathrm{cm}$ long strips. A mixture of $5 \% \mathrm{HNO}_{3}$ and $5 \% \mathrm{HCL}$, known as Aqua Regia, was prepared in a flask. Approximately $1 \mathrm{~g}$ of plastic strips were weighed and placed into a $200 \mathrm{~mL}$ beaker. 100 $\mathrm{mL}$ of aqua regia was added to the beaker containing the plastic bags and heated on a hot plate. The mixture was heated until it reached its boiling point, based on the observed formation of bubbles. The samples were cooled, and the solid phase separated from the liquid phase. This experiment was performed in triplicate for each of the plastic bags. The liquid phase was then subjected to elemental testing using the Atomic Absorption Spectrophotometer (AAS). The analytes tested for this research were $\mathrm{Cd}, \mathrm{Cr}$, and $\mathrm{Pb}$. The AAS was calibrated using stock solutions obtained from Fisher Scientific and are described in Table II.

TABLE II: CONSTITUENTS AND STOCK SOLUTIONS USED

\begin{tabular}{|c|c|c|c|}
\hline Polymer Class & Color & Use & Sample ID \\
\hline \multirow{6}{*}{$\begin{array}{c}\text { Low Density } \\
\text { Polyethylene } \\
\text { (LDPE) }\end{array}$} & Black & Grocery Bag & 1-Bl \\
\hline & Brown & Grocery Bag & $1-\mathrm{Br}$ \\
\hline & White & Grocery Bag & $1-W$ \\
\hline & Black & Trash Bag & $2-\mathrm{B} 1$ \\
\hline & White & Trash Bag & $2-W$ \\
\hline & Transparent & Pellet & $3-\mathrm{T}$ \\
\hline \multicolumn{4}{|c|}{$\begin{array}{l}=\text { Grocery } \mathrm{Bag}, 2=\text { Trash Bag, } 3=\text { Pellet } \\
\mathrm{Bl}=\text { Black, } \mathrm{Br}=\text { Brown, } \mathrm{W}=\text { White, } \mathrm{T}=\text { Transparent }\end{array}$} \\
\hline
\end{tabular}




\section{B. Extraction}

Samples tested for this experiment were 2-B1, 2-W, 3-T. These samples were selected because the acid digestion procedure indicated lead concentration in the trash bags rather than the grocery bags. Samples were sent to an external, accredited laboratory to perform an extraction and analysis on each of the provided plastic samples. The laboratory procedure, an inductively couple plasma-atomic emission spectrometry (ICP-AES), was performed in accordance with EPA Method 200.7, Revision 4.4. $1 \mathrm{~mL}$ of concentrated nitric acid was added to a $50 \mathrm{~mL}$ aliquot of a well-mixed and preserved digestion solution sample. The sample was then heated to a high temperature, making sure not to exceed $95^{\circ} \mathrm{C}$. The sample remained under heat until its volume was reduced by approximately one half. After sufficient volume reduction, the sample was set aside to cool and then gently refluxed for 15 minutes with $1 \mathrm{~mL}$ of $50 \%$ concentrated hydrochloric acid. Finally, the sample volume was diluted back to its original volume using deionized water and mixed well prior to analysis. Analysis using the ICP-AES method tested for the following analytes: $\mathrm{Cd}, \mathrm{Cr}$ and $\mathrm{Pb}$. [28]

\section{C. $X R F$}

The samples tested for this equipment were 2-B1, 2-W and 3-T. Testing using an X-Ray Fluorescence Spectrometer (XRF) was performed in accordance with the Background Fundamental Parameter (FP) method, patented by the instrument supplier, Shimadzu (Patent Pending: PCT/JP2013/78002, PCT/JP2013/78001). To prepare the sample, the plastic bags were trimmed and neatly folded and placed into the XRF so that the apparatus could test a layered sample of the plastic. The pellets were also tested but placed into a mylar cup for ease of containment. The XRF exposed each sample to X-rays, which in turn allowed for the sample itself to emit further x-rays due to component atoms of the sample. These $\mathrm{x}$-rays produced wavelengths that were each characteristic of a specific element. Investigation of these wavelengths confirmed presence of the following analytes: $\mathrm{Cd}, \mathrm{Cr}, \mathrm{Mn}$, and $\mathrm{Ni}$. The XRF did not pick up any wavelengths for $\mathrm{Pb}$. In addition to qualitative data, the XRF provided quantitative data based upon the intensity of emitted $\mathrm{X}$-rays fluorescence.

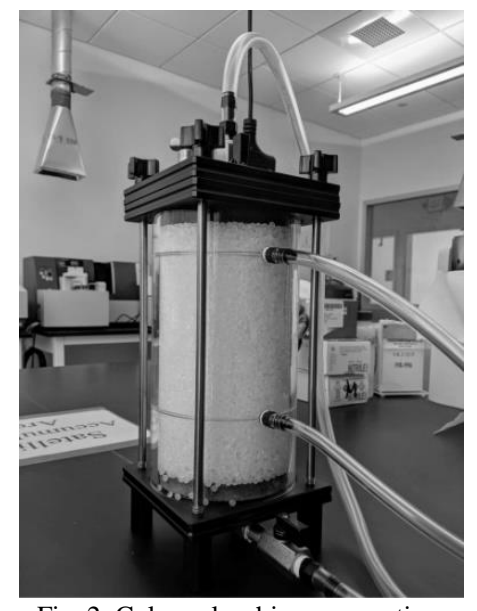

Fig. 2. Column leaching preparation.

\section{Column Leaching}

The column leaching test was performed only on the plastic pellets. The columns were filled with plastic pellets until they were tightly packed. The columns were then attached to a gravity head system as seen in Fig. 2, with one inlet tube feeding leachate from a holding tank and one outlet tube to allow for collection of the passed leachate. Based on the pore volume that was calculated to be one liter, it was determined that each time one liter of solution passed through the column, it would be tested for the selected heavy metals. The data would then be put into the Yalcin Leaching Model to predict the leaching behavior over an extended period of time. Each pore volume was tested twice to provide duplicate results. [29]

\section{E. Environmental Modelling}

"A Yalcin leaching model was formulated to capture the observed experimental leaching behavior of the contaminant exhibiting an initial increase in concentration followed by a decrease in concentration with further leaching until it reaches a low steady state concentration. The model is as follows:

$$
C(t)=C_{s}-C_{s} * e^{-K k_{b} t}+C_{0} * e^{-K k_{b} t}
$$

where $k_{b}$ is the dissolution rate coefficient $\left(\mathrm{min}^{-1}\right), K=\left(S / S_{0}\right)^{\mathrm{a}}$, $\mathrm{S}=$ Solid phase concentration $(\mathrm{mg} / \mathrm{g}), S_{0}=$ Initial solid phase concentration $(\mathrm{mg} / \mathrm{g}), \quad C_{s}$ is the effective saturation concentration (solubility) of contaminant $(\mathrm{mg} / \mathrm{L}), t$ is the time ( $\mathrm{min}$ ), and a is a dimensionless empirical constant" (Das 2007).

\section{REsults AND Discussion}

The acid digestion data revealed that only $\mathrm{Pb}$ was released from the plastic bags. The other analytes were in the non-detect range. The lead concentrations were in the $\mu \mathrm{g} / \mathrm{L}$ range which were below permissible limits for soil contamination. The data is present in Table III.

TABLE III: ACID DIGESTION DATA

\begin{tabular}{|c|c|c|c|c|c|}
\hline $\begin{array}{c}\text { Sample } \\
\text { ID }\end{array}$ & Dilution & Replicate & \begin{tabular}{|c|} 
Lead $(\mathrm{Pb})$ \\
Concentration \\
$(\mu \mathrm{g} / \mathrm{L})$
\end{tabular} & Mean & $\begin{array}{l}\text { Standard } \\
\text { Deviation }\end{array}$ \\
\hline \multirow{9}{*}{$1-\mathrm{Bl}$} & \multirow{3}{*}{ - } & 1 & \begin{tabular}{|l|l}
1.074 \\
\end{tabular} & \multirow[b]{3}{*}{2.061} & \multirow[b]{3}{*}{0.8561} \\
\hline & & 2 & 2.591 & & \\
\hline & & 3 & 2.519 & & \\
\hline & \multirow{3}{*}{$1 / 100$} & 1 & 0.285 & \multirow[b]{3}{*}{0.211} & \multirow[b]{3}{*}{0.0641} \\
\hline & & 2 & 0.169 & & \\
\hline & & 3 & 0.180 & & \\
\hline & \multirow{3}{*}{$1 / 10000$} & 1 & 0.131 & \multirow[b]{3}{*}{0.108} & \multirow[b]{3}{*}{0.0204} \\
\hline & & 2 & 0.101 & & \\
\hline & & 3 & 0.092 & & \\
\hline \multirow{9}{*}{$1-\mathrm{Br}$} & \multirow{3}{*}{ - } & 1 & 2.341 & \multirow[b]{3}{*}{2.672} & \multirow[b]{3}{*}{0.6821} \\
\hline & & 2 & 2.219 & & \\
\hline & & 3 & 3.457 & & \\
\hline & \multirow{3}{*}{$1 / 100$} & 1 & 0.128 & \multirow[b]{3}{*}{0.157} & \multirow[b]{3}{*}{0.0259} \\
\hline & & 2 & 0.178 & & \\
\hline & & 3 & 0.164 & & \\
\hline & \multirow{3}{*}{$1 / 10000$} & 1 & 0.270 & \multirow[b]{3}{*}{0.240} & \multirow[b]{3}{*}{0.0267} \\
\hline & & 2 & 0.217 & & \\
\hline & & 3 & 0.234 & & \\
\hline \multirow{9}{*}{$1-W$} & \multirow{3}{*}{ - } & 1 & 0.609 & \multirow[b]{3}{*}{1.096} & \multirow[b]{3}{*}{0.9947} \\
\hline & & 2 & 0.439 & & \\
\hline & & 3 & 2.241 & & \\
\hline & \multirow{3}{*}{$1 / 100$} & 1 & 0.128 & \multirow[b]{3}{*}{0.211} & \multirow[b]{3}{*}{0.0720} \\
\hline & & 2 & 0.251 & & \\
\hline & & 3 & 0.255 & & \\
\hline & \multirow{3}{*}{$1 / 10000$} & 1 & 0.342 & \multirow{3}{*}{0.323} & \multirow[b]{3}{*}{0.0204} \\
\hline & & 2 & 0.302 & & \\
\hline & & 3 & 0.325 & & \\
\hline
\end{tabular}

The extraction data proved similar to the digestion data 
where only $\mathrm{Pb}$ was detected by the ICP-AES as well. The extraction data is shown below in Table IV.

TABLE IV: EXTRACTION DATA

\begin{tabular}{|c|c|c|c|}
\hline Sample ID & Analyte & Results & $\begin{array}{c}\text { Reporting } \\
\text { Limit (mg/Kg) }\end{array}$ \\
\hline \multirow{3}{*}{$2-\mathrm{W}$} & $\mathrm{Cd}$ & $\mathrm{ND}$ & 4.00 \\
\cline { 2 - 4 } & $\mathrm{Cr}$ & $\mathrm{ND}$ & 8.40 \\
\cline { 2 - 4 } & $\mathrm{Pb}$ & $<12$ & 12.00 \\
\hline \multirow{3}{*}{$2-\mathrm{Bl}$} & $\mathrm{Cd}$ & $\mathrm{ND}$ & 4.40 \\
\cline { 2 - 4 } & $\mathrm{Cr}$ & $\mathrm{ND}$ & 8.10 \\
\cline { 2 - 4 } & $\mathrm{Pb}$ & $\mathrm{C}$ & 12.00 \\
\hline \multirow{3}{*}{$3-\mathrm{T}$} & $\mathrm{Cd}$ & $\mathrm{ND}$ & 0.17 \\
\cline { 2 - 4 } & $\mathrm{Cr}$ & $<0.49$ & 0.33 \\
\cline { 2 - 4 } & $\mathrm{Pb}$ & & 0.49 \\
\hline
\end{tabular}

The XRF data revealed a whole gamut of analytes, however $\mathrm{Pb}$ was not present in any of the samples. The results from the XRF are shown in Table V.

TABLE V: XRF TESTING DATA

\begin{tabular}{|c|c|c|c|c|c|c|c|c|}
\hline \begin{tabular}{|c|} 
Sample \\
ID
\end{tabular} & \begin{tabular}{|l|} 
Analyte \\
\end{tabular} & \begin{tabular}{l|} 
Composition \\
Results (\%)
\end{tabular} & $\begin{array}{c}\text { Sample } \\
\text { ID }\end{array}$ & Analyte & $\begin{array}{l}\text { Composition } \\
\text { Results (\%) }\end{array}$ & \begin{tabular}{|c|} 
Sample \\
ID
\end{tabular} & Analyte & \begin{tabular}{|l|} 
Composition \\
Results (\%)
\end{tabular} \\
\hline \multirow{20}{*}{ 2-Bl } & $\mathrm{Cr}$ & \begin{tabular}{|l|}
0.132 \\
\end{tabular} & \multirow{20}{*}{$2-W$} & $\mathrm{Cr}$ & 0.011 & \multirow{20}{*}{ 3-T } & $\mathrm{Cr}$ & ND \\
\hline & $\mathrm{Cd}$ & ND & & $\mathrm{Cd}$ & ND & & $\mathrm{Cd}$ & ND \\
\hline & $\mathrm{Ti}$ & 37.316 & & $\mathrm{Ti}$ & 18.35 & & $\mathrm{Ti}$ & - \\
\hline & $\mathrm{Ca}$ & 30.684 & & $\mathrm{Ca}$ & 79.339 & & $\mathrm{Ca}$ & - \\
\hline & $\mathrm{Si}$ & 17.931 & & $\mathrm{Si}$ & 0.812 & & $\mathrm{Si}$ & 37.119 \\
\hline & $\mathrm{Mg}$ & 6.435 & & $\mathrm{Mg}$ & 0.705 & & $\mathrm{Mg}$ & - \\
\hline & $\mathrm{Al}$ & 2.958 & & $\mathrm{Al}$ & 0.417 & & $\mathrm{Al}$ & 5.053 \\
\hline & $\mathrm{S}$ & 2.583 & & $\mathrm{~S}$ & 0.118 & & $\mathrm{~S}$ & 32.276 \\
\hline & $\mathrm{K}$ & 0.782 & & $\mathrm{~K}$ & - & & $\mathrm{K}$ & 12.941 \\
\hline & $\mathrm{Fe}$ & 0.709 & & $\mathrm{Fe}$ & 0.182 & & $\mathrm{Fe}$ & 1.898 \\
\hline & $\mathrm{Hf}$ & 0.185 & & $\mathrm{Hf}$ & - & & $\mathrm{Hf}$ & 3.825 \\
\hline & $\mathrm{Zn}$ & 0.118 & & $\mathrm{Zn}$ & 0.059 & & $\mathrm{Zn}$ & 1.303 \\
\hline & $\mathrm{Cu}$ & 0.091 & & $\mathrm{Cu}$ & - & & $\mathrm{Cu}$ & - \\
\hline & $\mathrm{P}$ & 0.077 & & $\mathrm{P}$ & - & & $\mathrm{P}$ & - \\
\hline & $\mathrm{Ni}$ & 0 & & $\mathrm{Ni}$ & 0 & & $\mathrm{Ni}$ & 0 \\
\hline & $\mathrm{Mn}$ & 0 & & $\mathrm{Mn}$ & 0 & & $\mathrm{Mn}$ & 0 \\
\hline & $\mathrm{Sr}$ & - & & $\mathrm{Sr}$ & 0.008 & & $\mathrm{Sr}$ & - \\
\hline & Os & - & & Os & - & & Os & 2.836 \\
\hline & $\mathrm{Hg}$ & - & & $\mathrm{Hg}$ & - & & $\mathrm{Hg}$ & 1.904 \\
\hline & $\mathrm{Ge}$ & - & & $\mathrm{Ge}$ & - & & $\mathrm{Ge}$ & 0.845 \\
\hline
\end{tabular}

Based on all the testing, it is hypothesized that the $\mathrm{Pb}$ concentrations found in a plastic bag are being sourced from the black dye and not from the plastic bag itself. The column leaching data is not presented in this paper as it is an ongoing test and will be presented at a later time.

\section{CONCLUSION}

This research indicated that plastic did not release any heavy metals above permissible limits for soil. The $\mathrm{Pb}$ which was present in the plastic bags during the acid digestion and extraction was primarily from the dye and not from the plastic itself. This is an ongoing research project where column leaching tests are being conducted to evaluate the long-term leaching of contaminants from plastic bags and pellets. The Yalcin leaching model will be able to predict the concentration of the contaminants for hundreds of pore volumes. This data will give indication of the long-term leaching potential of plastic. Future research will be conducted to evaluate the leaching potential of plastic when placed in asphalt as a replacement for bitumen.

\section{CONFLICT OF INTEREST}

The authors declare no conflict of interest.

\section{Author CONTRIButions}

Research and literature review were conducted collaboratively by all three authors. Laboratory procedures were determined by Gabriela Kuran and Catarina Figueiredo Mendes under the supervision and final review of Dr. Gautham Das. Unless otherwise stated, Gabriela Kuran and Catarina Figueiredo Mendes carried out all laboratory preparation and testing. All three authors wrote the paper and reviewed it upon final submittal.

\section{REFERENCES}

[1] R. C. Thompson et al., "Philosophical transactions: Biological sciences," Plastics, the Environment and Human Health, vol. 364, no. 1526, Jul. 27, 2009, pp. 2153-2166

[2] PlasticsEurope, European House-Ambrosetti, op. cit. note 7.

[3] American Chemistry Council, op. cit. note 5.

[4] C. J. Moore et al., Plastics, the Environment and Human Health, pp. 2153-2166 Vol. 364, No. 1526,

[5] M. A. Browne et al., "Accumulation of microplastic on shorelines worldwide: Sources and sinks," Environmental Science \& Technology, vol. 45 , no. 21 , pp. 9175-9179, 2011.

[6] J. Hopewell et al., "Plastics recycling: Challenges and opportunities," Phil. Trans. R. Soc. B, vol. 364, pp. 2115-2126, 2009.

[7] D. Enviros et al., "Review of England's waste strategy," Environmental Report under the 'SEA' Directive, p. 96, London, UK: DEFRA, 2006

[8] D. K. A. Barnes et al., "Accumulation and fragmentation of plastic debris in global environments," Phil. Trans. R. Soc. B, vol. 364, pp. 1985-1998, 2009.

[9] R. Dilli, "Comparison of existing life cycle analysis of shopping bag alternatives," Final Report, Hyder Consulting Pty Ltd., Australia, 2007.

[10] N. Ahmad et al., "Heavy metal assessment of leachates of some plastic toys purchased from different districts of UP," India. Int. Res. J. Environ. Sci., vol. 1, no. 4, pp. 32-36, 2012.

[11] S. Sribala, "Plastic roads: India's radical plan to bury its garbage beneath the streets," The Guardian, 2018.

[12] V. S. Punith and A. Veeraragavan, "Behavior of asphalt concrete mixtures with reclaimed polyethylene as additive," J. Mater. Civ. Eng., vol. 6, p. 500e507, 2007

[13] R. Vasudevan et al., "A technique to dispose waste plastics in an ecofriendly way e application in construction of flexible pavements," Constr. Build. Mater, vol. 1, p. 311e320, 2012.

[14] S. Smith, Plastic Bags NSW Parliamentary Library Research Service, Briefing Paper No 5/04, 2004.

[15] ] United Nations Environment Programme (UNEP), "Selection, design and implementation of economic instruments in the solid waste management sector in Kenya - The case for plastic bags," 2005.

[16] R. M. Miller, "Plastic shopping bags: An analysis of policy instrument for plastic bag reduction," Thesis Submitted for M.Sc. in Sustainable Development. Faculty of Geosciences, Universiteit Utrecht, 2012.

[17] H. Takada, "Call for pellets! International pellet watch global monitoring of POPs using beached plastic resin pellets," Marine Pollution Bulletin, vol. 52, pp. 1547-1548, 2006.

[18] J. G. B. Derraik, "The pollution of the marine environment by plastic debris: A review," Marine Pollution Bulletin, vol. 44, pp. 842-852, 2002.

[19] M. Whitt et al., Leaching of Heavy Metals Contaminants in Recycled Polyethylene Terephthalate Used for Food Packaging, 2014.

[20] M. López et al., "Heavy metal content in rubbish bags used for separate collection of biowaste," Waste Manage, vol. 30, no. 8-9, pp. 1450-1456, 2010.

[21] L. Jarup, "Hazards of heavy metal contamination," Br Med Bull., vol. 68, pp. 167-182, 2003.

[22] R. G. Cooper and A. P. Harrison, "The exposure to and health effects of antimony," Indian Jour. Occup. Environ. Med., vol. 13, no. 1, pp. 3-10, 2009.

[23] M. Al-Qutob et al., "Determination of different trace heavy metals in children's plastic toys imported to the West Bank/Palestine by ICP/MS-environmental and health aspects," J. Environ. Prot, vol. 5, no. 12, pp. 1104-1110, 2014.

[24] A. Kumar and P. Pastore, "Lead and cadmium in soft plastic toys," Curr. Sci., vol. 93, no. 6, pp. 818-822, 2007.

[25] H. Sakurai et al., "Digestion of plastic materials for the determination of toxic metals with a microwave oven for household use," Anal. Sci., vol. 22, no. 2, pp. 225-228, 2006. 
[26] X. Cheng et al., "Assessment of metal contaminations leaching out from recycling plastic bottles upon treatments," Environ. Sci. Pollut. Res., vol. 17, no. 7, pp. 1323-1330, 2010.

[27] S. Khan and A. R. Khan, "Contamination of toxic heavy metal in locally made plastic food packaging containers," Glob. J. Sci. Front. Res.: B Chem., vol. 15, no. 1, pp. 19-24, 2015.

[28] N. Ahmad et al., "Heavy metal assessment of leachates of some plastic toys purchased from different districts of UP," India. Int. Res. J. Environ. Sci., vol. 1, no. 4, pp. 32-36, 2012.

[29] S. G. Kang and J. X. Zhu, "Metals contamination and leaching potential in plastic toys bought on the Beijing market," Adv. Mater. Res., vol. 878, pp. 112-121, 2014.

Copyright $\odot 2019$ by the authors. This is an open access article distributed under the Creative Commons Attribution License which permits unrestricted use, distribution, and reproduction in any medium, provided the original work is properly cited ( $\underline{\text { CC BY 4.0) }}$.

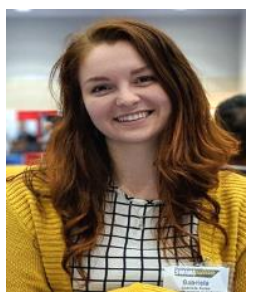

Gabriela Kuran was born in Brockton Massachusetts in August of 1997. She grew up on the Massachusetts South Shore and remained there until moving to Boston to begin her college career in September of 2015. Gabriela is currently a second-semester senior at Wentworth Institute of Technology (WIT) where she will be graduating in August of 2019. She will be graduating with a Bachelor of Science in civil engineering and a minor in environmental engineering.

Gabriela has worked two internship periods during her time at WIT. Both internships were spent at CLE Engineering, Inc. in Marion, MA. Due to an acquisition during her first internship, the company is now known as Foth-CLE Engineering Group. Her work primarily involved CAD drafting on coastal and marine engineering projects such as large dredging projects on both the east and west coast of the US. Gabriela has also achieved a publication which she co-wrote with college professor Francis J. Hopcroft during her sophomore year at WIT, titled Environmental Engineering Dictionary of Technical Terms and Phrases: English to Polish and Polish to
English (Boston, MA: Momentum Press 2016). Her research interests lie within sustainability, green building, and water quality.

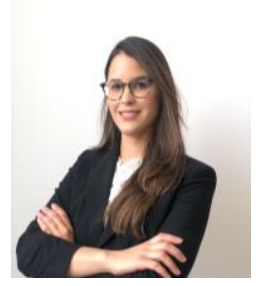

Catarina Figueiredo Mendes was born in Brazil and migrated to the United States of America to attend school at Wentworth Institute of Technology in pursuit of a civil engineering degree in 2015 Catarina is expected to graduate in the summer of 2019, which a Bachelor of Science in civil engineering.

During her junior year as a civil engineering major at Wentworth Institute of Technology, Catarina has worked in structural engineering roles at DESMAN Parking Specialists, and site/civil engineering roles at the Department of Public Works of the City of Cambridge. Her interests in sustainability pushed her to obtain her LEED Green Associate certification. Her excellence in academics has earned her a membership with the Phi Theta Kapp student society. Catarina's interests include sustainability, sustainable buildings, ground and soil remediation and water quality.

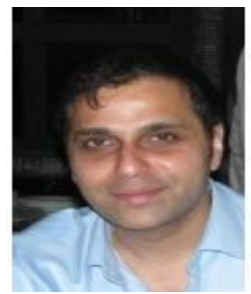

Gautham P. Das has served as associate professor of civil and environmental engineering at Wentworth Institute of Technology (WIT) in Boston, Massachusetts since August 2008. Dr. Das received a doctorate from the University of North Carolina at Charlotte. Dr. Das is currently an elder endowed professor at WIT.

Prior to starting his teaching career, Dr. Das worked for environmental consulting firms in North Carolina and Boston. His expertise lies in water resources, hydraulic engineering and environmental remediation. $\mathrm{He}$ is active in the Water Environment Federation, the New England Water Environment Association and the American Society for Engineering Education.

He has authored numerous technical papers on various civil and environmental engineering subjects that have been presented at technical conferences and appeared in the Proceedings of those conferences. 